\title{
¿Por qué el tema del suicidio importa a la filosofía?
}

\section{Why does suicide matter to philosophy?}

\author{
Gabriel Ocampo Sepúlveda*
}

\begin{abstract}
*Doctor en Filosofía, Magíster en Filosofía, Profesor en la Universidad del Quindío. Investigador del Grupo de Investigación en filosofía política, social y jurídica: POLITIA -Universidad del Quindío. gabriel.os9@gmail.com, Colombia.
\end{abstract}

Cómo citar: Ocampo, G.(2017) ¿Por qué el tema del suicidio importa a la filosofía? Inciso, 19 (1): 148-157.

\section{Resumen}

La pregunta que acá se plantea es la siguiente: ¿Por qué el tema del suicidio importa a la filosofía? La idea en este escrito es llamar la atención sobre el hecho de que tal vez las respuestas del porqué del suicidio y del suicida no habría que buscarlas única y exclusivamente en el ámbito de la carne. Tal vez, sea hora de que también se les pregunte y les deje hablar a la filosofía, a las artes y a las religiones sobre este tema. En esta instancia, se aboga por la filosofía.

Palabras clave: Suicidio, naturalismo, antropología filosófica, biopolítica, Autonomía
The question that is developed here is: Why does the subject of suicide matter to philosophy? The idea in this paper is to draw attention to the fact that perhaps the answers to the question of suicide and the person who seeks to commit suicide should not be sought solely and exclusively in the realm of the flesh. Perhaps, it is time to ask and listen on this topic to philosophy, art and religion. In this instance, I advocate for philosophy.

Keywords: Suicide, naturalism, Philosophical Anthropology, biopolitics, Autonomy. 
La filosofia sirve de antídoto contra la tristeza.

Y hay quienes creen aún en la profundidad de la filosofia.

Emil Ciorán (Cioran, 1990)

\section{Introducción}

La pregunta que quisiera plantearme acá no podría ser otra que la siguiente: ¿Por qué el tema del suicidio importa a la filosofía en una sociedad medicalizada y farmacodependiente como la nuestra? Si bien puede parecer muy fuerte el término farmacodependiente, no se podría negar que en nuestra época, hemos llegado a creer que todo aquello considerado una patología, anormalidad o cosa que se le parezca, tiene una explicación en la carne y una solución en las combinaciones de substancias químicas. Es decir, todo padecimiento se reduce a desbalances químicos y toda solución radica en encontrar aquellas substancias químicas que regresan el equilibrio. En ese estado de cosas, la ciencia trata con procesos no con personas, o como dice Emil Cioran, "Ser objetivo es tratar al prójimo como se trata a un objeto, a un muerto, es comportarse con él como un sepulturero" (Ciorán, 1972). Allí, la reflexión filosófica no tiene nada que hacer.

La idea en este escrito no es caricaturizar o deslegitimar las ciencias médicas y forenses y la forma de abordar el tema del suicidio, sino, llamar la atención sobre el hecho de que tal vez las respuestas del porqué del suicidio y del suicida no habría que buscarlas única y exclusivamente en el ámbito de la carne. Tal vez, sea hora de que también se les pregunte y se les deje hablar a la filosofía, a las artes y a las religiones sobre este tema. En esta instancia, abogo por la filosofía y las múltiples perspectivas desde donde se podría abordar.

Cabe resaltar que no se pretende agotar la totalidad de las reflexiones filosóficas sobre esta temática, tan solo motivar el ejercicio reflexivo. Asimismo, habría que señalar la gran cantidad de posturas que han surgido al interior de la reflexión filosófica en la que no sería posible encontrar una posición común y universal. Lo importante del ejercicio filosófico se traduce en la reflexión misma.

Alo largo del escrito, se habrá de llamar la atención entre varios enfoques desde donde se podría abordar un mismo fenómeno y que, en cierto sentido, determinarían un tipo de sensibilidad y tratamiento del objeto de estudio. En una disputa ya milenaria, siempre se ha encontrado en escena la reflexión filosófica en contraposición con ciertas posturas positivistas o naturalistas. Como se habrá de ver, al tema en particular del suicido no le ha sido ajena esta disparidad de enfoques. Posteriormente, se hará un esbozo muy somero de la forma cómo los estudios de antropología filosófica podrían enriquecer la reflexión sobre el objeto de estudio que acá nos atañe. Así, en un sentido menos tradicional del análisis filosófico, el tema del suicidio no tendría por qué considerarse desde un enfoque meramente moral o humanista ni mucho menos personal, patológico u hormonal, hoy día, ha llegado a ser un asunto político y de administración pública de la vida donde cada cuerpo que fallece, se traduce en una perdida para la economía en términos de fuerza de trabajo, en riqueza, en productividad. $Y$ finalmente, se busca cerrar este escrito con una de esas forma alternas de reflexión que ayudarían a abrir más el espectro de la indagación sobre esta temática, nos referimos al suicidio como un signo de autonomía. Así, una sociedad que se jacta de sus libertades, no se podría dejar de lado una discusión mucho más profunda sobre el ineludible carácter paradójico de la autonomía. Es decir, a través de esta característica fundamental de nuestro ser, subyace en nosotros, "la posibilidad de salvarnos o de perdernos" (Ciorán, 1972, pág. 36). El enfoque que guía este escrito se funda en una visión afirmativa del acto suicida, no obstante, no es la única. Es 
decir, este carácter libre del suicidio no pretende obviar que existen posturas como la de Sartre o Spinoza en las que se evidencia la imposibilidad de la libertad en el acto suicida. Queda la tarea pendiente y fundamental de contrastar estas posturas para enriquecer la reflexión. Quisiera reiterar que la pretensión es motivar la reflexión multidisciplinar sobre el tema del suicidio y no sentar cátedra, de allí, que no se ha pretendido alcanzar conclusiones, sino, dejar abiertos los interrogantes.

Para iniciar, y en relación con muchas de las preocupaciones que atañen a la filosofía, recordemos una cita del filósofo francés Albert Camus, cuando da una descripción del "hombre actual" preso entre los engranajes de la vida moderna y superracionalizada: levantarse, tranvía, trabajo, comer, tranvía, comprar, comprar, trabajo, lunes, martes, miércoles...; de pronto todo se derrumba, se revela en toda su crudeza el absurdo y el vacío de semejante existencia. De ahí, el interrogante fundamental: ¿vale la pena vivir? (Camus, 1994: 15). Al respecto, considera que,

Existe un sólo problema filosófico verdaderamente serio: el suicidio. Juzgar si la vida merece o no merece ser vivida es responder a la cuestión fundamental de la filosofía [...] yo nunca he visto morir a un hombre por defender el argumento ontológico ni epistemológico [...] por tanto, pienso que el sentido de la vida es la cuestión más urgente (Camus, 1994: 15).

\section{Una pelea perdida: reflexión filosófica vs. Naturalismos}

Por lo general, se asume que el campo del saber al que compete "el problema del suicidio" no es otro que la medicina y muy especialmente, la psiquiatría, aunque, hoy día, las neurociencias han estado tomando la delantera en cuanto a sus hipótesis sobre el cerebro y la psique de los suicidas. Por el contrario, en la conciencia colectiva, a la filosofía se la ha descartado como ámbito de reflexión sobre este fenómeno. Lo que cuenta para la opinión pública son las patologías, las enfermedades, los números, las estadísticas, las gráficas, en pocas palabras, las explicaciones supuestamente objetivas.

Desde una posición muy crítica sobre estos reduccionismos naturalistas que en nuestros tiempos ha sufrido el drama humano, considera Manfred Frank (Frank, 1995) que las formas de conocimiento no filosófico -como las que pretenden las ciencias de la naturaleza y la técnica- no han sido muy adeptas a la idea de la individualidad. De hecho, la ciencia exige más bien por motivos metodológicos la exclusión de lo individual, de lo particular, de los pormenores y detalles del drama de cada uno. Sólo tiene valor aquello que puede generalizarse. Si cabe sospechar que el carácter científico se alza sobre una exclusión de la individualidad, ciertamente cabría concluir que ya no resultan muy iluminadores los diagnósticos que se puedan ofrecer solamente desde estos procesos de racionalización sobre el suicidio.

Bien sostiene Joseph Gevaert (Gevaert, 1995) que frente a la gigantesca empresa cultural que ha implicado la reflexión naturalista y técnica sobre el ser de la individualidad,

Muchos siguen sin duda soñando en que el progreso científico y el progreso técnico realizarán casi automáticamente una existencia mejor, o que la elaboración científica de nuevas estructuras proporcionará la clave última y definitiva para superar todas las miserias que nos aquejan. Por otra parte, también aumentan cada día el número de los que toman sus distancias respecto a la fe absoluta en las ciencias; están convencidos de que hay en nuestro ser individual ciertos problemas que jamás podrán comprenderse y menos todavía resolverse a través de unos cambios externos 
y puramente materiales [...] lo anterior, podría ser una muestra en que el aumento vertiginoso de los conocimientos técnicos $\mathrm{y}$ analíticos de la existencia humana y del progresivo perderse por entre los laberintos de las especializaciones van acompañados de una creciente incertidumbre respecto a lo que constituye el ser profundo y último de nosotros mismos (Gevaert, 1995: 12).

En ese mismo sentido, considera Heidegger que, allí donde actualmente reina la incertidumbre y el desconcierto respecto de la imagen de un sí mismo, la reflexión filosófica ha perdido su poca legitimidad para tratar de abordar el sentido del ser o de la vida misma. No obstante, sostiene que,

Ninguna época ha sabido conquistar tantos y tan variados conocimientos sobre el hombre como la nuestra [...] Sin embargo, ninguna época ha conocido al hombre tan poco como la nuestra. En ninguna época el hombre se ha hecho tan problemático como en la nuestra (Heidegger, 1975: 87).

En términos generales, no se puede negar que, de la reflexión filosófica se dice que es mera palabrería ya que no trata con "hechos observables", para nada ligado al mundo de los fenómenos empíricos, no se trata de otra cosa sino de meras especulaciones vacías, semejantes a las disputas extra-físicas tendientes a dirimir cuestiones retóricas, poco útiles y prácticas para la vida. Bien sostiene Maine de Biran, filósofo francés del siglo XIX, que cualquier estudio sobre el ser del individuo que no se reduzca a la carne, es un viaje, "por un país desierto e inculto que los viajeros tienen poca curiosidad de visitar" (Birán, 1932: 18).

Asumiendo que la reflexión filosófica tiene algo que decir sobre este tema tan acuciante para nuestra sociedad, me atrevería a sostener que uno de los primeros aspectos a los que se tendría que acudir para dar razones sobre el suicidio y el suicida no podría ser otro que los supuestos acerca del yo. Parodiando un poco el adagio popular: "dime que concepto de yo te fundamenta y te diré quién crees que eres", aduciendo con ello, a la historicidad de esta Idée-force, como lo llama Taylor (Taylor, 1996), pero, aunque concepto histórico, fundamental para nuestra constitución y auto-comprensión. Según el filósofo canadiense, "identidad moderna o la noción moderna de lo que es ser un agente humano, una persona o un yo" (Taylor, 1996: 17) tendrá que tener que escudriñar en las entrañas más profundas de lo que nos constituye como seres modernos

\section{Hacia una antropología filosófica del suicida}

Pero, preguntémonos, ¿por qué son tan decisivas para nuestra vida las caracterizaciones que hagamos de nuestro yo -de nuestra manera de hacernos asequibles a otros? ¿Cuál es el motivo de que los cambios que sobrevienen en estas caracterizaciones sean temas de interés tan preponderante? (Gergen, 1991). En relación con los interrogantes, sostiene Gevaert que,

\section{Quizás estemos asistiendo actualmente a la más amplia crisis de identidad que ha atravesado nunca el hombre, crisis en la que se ponen en discusión o quedan marginados muchos de los fundamentos seculares de la existencia [...] por tanto [...] es preciso recuperar la secular certeza del hombre, pensarla de nuevo hasta el fondo y enriquecerla con todas las nuevas interpretaciones. En el centro está el problema del significado de la existencia; pero ese problema no puede aclararse más que a la luz del ser mismo del hombre (Gevaert, 1995: 12-13).}

Dentro de todo el bagaje del sentido común, se acepta que, en nuestra condición de seres humanos comunes y corrientes, poseemos la facultad de razonar, tenemos emociones, intenciones, conciencia moral, buscamos ser reconocidos y a su vez, otros buscan su reconocimiento en nosotros, etc. Es decir, estos 
conceptos desempeñan un papel decisivo en nuestra manera de relacionarnos con los demás. Sin embargo, de un tiempo para acá, se han puesto en entredicho todas las premisas tradicionales sobre la naturaleza de la identidad personal, hasta tal extremo, que los conceptos mismos de verdad, de objetividad, de saber, y aún la idea de un ente individual, dotado de determinadas propiedades mentales, de corporalidad, de conciencia, de subjetividad están corriendo el riesgo de ser eliminados de nuestro panorama cultural. Y esto significa algo inquietante para nuestra vida en común.

Así, al centrarse uno en un estado de cosas más general, nos sorprende advertir que este cataclismo contemporáneo guarda un paralelismo con otros cambios no menos importantes en las formas actuales en que se conducen y relacionan las personas que sufren en carne propia la "desintegración o disolución de su concepción de yo". Sin embargo, de igual forma, se podría sostener que anejo al cataclismo, se parece asumir con gran fervor las nuevas perspectivas que se avizoran, lo que se daría en llamar con Foucault, las estéticas de sí, el carnaval de las técnicas y tecnologías de sí.

Además, a decir de Gergen, los logros tecnológicos a lo largo del siglo han producido una alteración radical en nuestra forma de revelarnos a los demás. Hoy estamos sometidos a una tremenda andanada de estímulos sociales que han estado sentando las bases tanto de los enormes cambios en nuestra experiencia cotidiana de nosotros mismos y de los demás, como del desenfrenado relativismo que se ha tomado tanto la esfera académica como, cada vez más, la esfera ética, moral, política y social. En ese sentido, los cambios rara vez se limitan a un sector, pues, reverberan en toda la cultura y se van acumulando lentamente hasta que un día nos damos cuenta que algo se ha trastocado y que ya no se puede recuperar lo perdido. De hecho, nuestro vocabulario relativo a nuestra propia comprensión se ha modificado notoriamente a lo largo del siglo $\mathrm{XX}$, al igual que, durante los que llevamos del presente siglo, y con éste, el carácter de los intercambios sociales (Gergen, 1991: 115).

Esta creciente saturación de la cultura ha puesto en entredicho todas nuestras premisas previas sobre el yo, convirtiendo en algo extraño las pautas de relación tradicionales. En últimas, no deja de ser evidente que se ha estado forjando una nueva cultura: unas nuevas formas de ser, de pensarse, de sentirse, de narrarse, construirse y recrearse, etc.

Pero, preguntémonos nuevamente, ¿por qué son tan decisivas para nuestra vida las caracterizaciones que hagamos de nosotros mismos-denuestramanera dehacernos asequibles a otros? ¿Cuál es el motivo de que los cambios que sobrevienen en estas caracterizaciones sean temas de interés tan preponderante? (Gergen, 1991). De hecho, la cultura actual ha producido, en su breve existencia, un cuerpo de obras rico, audaz, exuberante, a través de todo el campo de las artes. Ha puesto sus límites sobre un número de complacientes certezas, enfrentando abiertamente algunas totalidades paranoicas, contaminando algunas purezas celosamente protegidas, atacando ciertas normas opresivas y sacudiendo ciertos fundamentos de aspecto bastante frágil. Como resultado, ha dejado perplejos a aquellos que sólo sabían bien quiénes eran y desarmó a los que necesitaban saber quiénes eran frente a aquellos demasiado ansiosos de decírselo. Produjo, en el mismo movimiento, un escepticismo vigorizador y paralizante, y descentró la soberanía del 'yo', al menos en teoría, por medio de un fuerte relativismo cultural que se ha tornado impotente.

De tal suerte, los movimientos culturales actuales al buscar conmocionar los fundamentos a posiciones ya establecidas y consideradas tradicionales, inevitablemente se han encontrado 
sacando la alfombra debajo de sí mismo, se han quedado sin mayores razones para resistir y existir, y han desarmado el poder de lo local, lo regional y lo idiosincrático, ayudando así a la homogenización llamada 'globalización' o 'americanización' del mundo. Además, al tiempo que libertario y determinista, los movimientos de contracultura han soñado con que el individuo se libere de las obligaciones, desplazándose delirantemente de una posición a otra, mientras sostiene que el sujeto es el mero efecto de fuerzas que lo constituyen por completo. Por tanto, nos ha dejado en la paradoja de vernos obligados a la libertad de ser y la impotencia de no poder ser frente a las fuerzas que lo constituyen todo. Como sostiene John Lyons, "lo que principalmente se ha perdido ha sido la sensación de que el yo tiene su escenario sobre el cual sufrir su propio drama" (Lyons, 1978: 16).

En consecuencia, hay algo que no se puede ocultar y a lo que tendría que acudirse para explicar el fenómeno del suicidio y el suicida y es la crisis que se ha producido en la concepción común de la comprensión humana, es decir, sobre la verdad, la objetividad, la identidad, la moral, la ética, problemas relacionados y muchísimos más. Anteriormente, por ejemplo, el problema de cómo se comprenden las personas entre sí y cómo comprenden el mundo que las rodea parecía relativamente sencillo. El lenguaje expresa ideas y sentimientos, se afirmaba; comprender el lenguaje es comprender la mente del que lo emplea, y el lenguaje de un individuo es capaz de transmitir una verdad objetiva. No obstante, a raíz de las diversas conmociones que ha sufrido la vida, hoy se hace difícil sustentar tales premisas. No resulta claro cómo conocen las personas la mente de los demás, y cómo pueden describir objetivamente el mundo fuera de ellas, si es que se puede decir que hay allí un mundo fuera de nosotros. Todo cuanto parecía transparente hace muchísimos años, hoy se ve bastante confuso.
Es un hecho, que la mayoría de las concepciones que apuntalaban las metas tradicionales, por ejemplo, vida de aprendizaje, vida laboral, vida familiar, vida social, vida política han sufrido un gran remesón. Para algunos, la desaparición de los presupuestos tradicionales es un acontecimiento casi catastrófico: apartarse de los antiguos ideales es promover el caos, primero, en el mundo personal y después, en la sociedad en general. Otros, por el contrario, ven en ello signos estimulantes de que la historia se encuentra en un punto de no-retorno donde no hay sino nuevas posibilidades, es decir, una nueva era.

\section{El suicidio: ¿un problema político?}

Visto desde otra óptica, para Foucault, el tema del suicidio no es un asunto meramente moral o humanista ni mucho menos personal, patológico $\mathrm{u}$ hormonal, ha devenido en una sociedad biopolítica como la nuestra, en un problema político y de administración pública de la vida donde cada cuerpo que fallece, se traduce en una perdida para la economía en términos de fuerza de trabajo, en riqueza, en productividad. Al respecto, Anna Quintanas sostiene que:

$$
\begin{aligned}
& \text { Foucault destaca que no es posible } \\
& \text { comprender nuestra forma actual de } \\
& \text { experienciar la muerte si no somos } \\
& \text { conscientes de la influencia que ha ejercido } \\
& \text { sobre ella el hecho de que la biopolítica } \\
& \text { se haya convertido en una de las formas } \\
& \text { principales de ejercicio del poder en nuestra } \\
& \text { sociedad. (Quintanas, 2010: 172). }
\end{aligned}
$$

Precisamente, para el filósofo francés, "Ahora es en la vida y a lo largo de su desarrollo donde el poder establece su fuerza; la muerte es su límite, el momento que no puede apresar" (Foucault, 1991: 167). En otras palabras, según Foucault, si en nuestra sociedad la muerte se ha convertido en un tabú, es precisamente por este protagonismo creciente que ha ido adquiriendo la administración de la vida. Cuando la gestión 
misma de la vida deviene el objetivo principal del poder, la muerte se convierte en un ámbito incómodo (Quintanas, 2010: 173).

En efecto, para Quintanas, parafraseando al filósofo francés,

La causa del hecho de que la muerte actualmente haya quedado recluida dentro de los muros de la intimidad, de lo privado, de lo poco visible -como si la muerte contuviera algo de vergonzoso que debiera esconderse 0 , al menos, no prodigarse-, debería buscarse, principalmente, dentro de la profunda transformación de los mecanismos de poder que se produjo a partir del siglo XVIII. (Quintanas, 2010: 172)

Y continúa:

A partir de entonces, ya no se tratará tanto de «hacer morir o dejar vivir», sino más bien de «hacer vivir y dejar morir», puesto que la biopolítica es un tipo de poder que tiene como objetivo principal la gestión de la vida, tanto de los individuos a nivel particular, como de la población en su conjunto. Administrar, gestionar y regular la vida, será el epicentro de esta nueva forma de ejercicio del poder. Se trata de un poder eminentemente centrado en la vida, y que se ejerce directamente sobre ella. (Quintanas, 2010: 173).

Al respecto sostiene Foucault que en el contexto histórico de la sociedad biopolítica, el suicida genera un quiebre con los gobernantes quienes administran su vida. De hecho, en una sociedad como la nuestra, donde todos los aspectos de la vida tienden a quedar perfectamente planificados, resulta paradójicamente escandaloso que un individuo pretenda organizar su muerte y hablar de los preparativos de la misma. (Quintanas, 2010, pág. 179). Para este:

No hay que asombrarse si el suicidio antaño un crimen, puesto que era una manera de usurpar el derecho de muerte que sólo el soberano, el de aquí abajo o el del más allá, podía ejercer- llegó a ser durante el siglo XIX una de las primeras conductas que entraron en el campo del análisis sociológico; hacía aparecer en las fronteras y los intersticios del poder que se ejerce sobre la vida, el derecho individual y privado de morir. Esa obstinación en morir, tan extraña y sin embargo tan regular, tan constante en sus manifestaciones, por lo mismo tan poco explicable por particularidades o accidentes individuales, fue una de las primeras perplejidades de una sociedad en la cual el poder político acababa de proponerse como tarea la administración de la vida (Foucault, 1991: 167-168).

De tal suerte, se podría sugerir, como bien argumenta el mismo Foucault, la necesidad de buscar formas alternas de reflexionar sobre la experiencia de la muerte que vayan más allá de los caminos preestablecidos por los dispositivos de la gubernamentalización que dirigen nuestro actual modelo de una sociedad de la auto-gestión. Justamente, habría que llamar la atención en la necesidad de interrogarse críticamente sobre el carácter unidimensional de los caminos trazados por estos dispositivos de la administración de la vida que nos impulsa, no sólo a convertir la muerte en un tabú sobre el que cabe pronunciarse lo menos posible, sino también en un final aséptico, altamente tecnificado, y dirigido por toda una serie de protocolos sanitarios preestablecidos, ante los que no existe más opción que la de someterse pasivamente a ellos (Foucault, Un placer tan sencillo, 1999). Para este, habría que preguntarse por la posibilidad de contemplar la muerte cómo la última oportunidad de experimentar de otra manera los últimos segundos de la vida, más allá de estos parámetros uniformadores prediseñados por la sociedad normalizadora/administradora en la que vivimos (Quintanas, 2010: 179).

Es decir, habría razones suficientes para abogar por que el tema del suicidio y el suicida se deban 
abordar desde múltiples perspectivas y de tal suerte, tratar de liberarlo de las garras de las definiciones meramente naturalistas, jurídicas o moralistas y de la carne. Tendría que reconocerse que el suicidio como patología o enfermedad mental, emocional, psicológica o psiquiátrica, es una construcción cultural bastante reduccionista. $\mathrm{O}$ en esa misma tónica, habría que abogar por descriminalizar el acto suicida como tal. De hecho, muchos estudios genealógicos han mostrado como nuestros marcos jurídicos y culturales han pretendido llevar al acto suicida al estrecho marco de lo ilegal y prohibido, ya que no han dejado de ser una versión secularizada del modelo judeo-cristiano del suicida como pecador. En ese sentido, en el mejor de los casos, con el fin de salvaguardar la dignidad del suicida y la de sus familias, habría que abordar el tema del suicidio en relación con la autonomía y no como una mera patología, mental, moral o peor aún, un problema legal. O como bien sostiene Foucault:

Debido a la mezquina realidad a la que se somete al suicidio en la era [...] del tabú de la muerte, éste no puede dejar tras de sí más que humillación, trámites sórdidos y marcas descorazonadoras: policía, autopsias, silencios y vergüenzas. Se interpreta que quien lo ha practicado sólo lo puede haber llevado a término desde una asfixiante infelicidad que le ha puesto en contra de la vida. Así, el suicido queda hoy envuelto por lo más deprimente y denigrante. (Foucault, Un placer tan sencillo, 1999: 199).

\section{Hacia una estética de la autonomía}

Precisamente, una de esas forma alternas de reflexión tendría que presentarse en el ámbito de la autonomía. Así, una sociedad que se jacta de sus libertades tendría que asumir el hecho ineludible del carácter paradójico de esta, de esa doble cara del acto autónomo "que comporta la posibilidad de salvarnos o de perdernos" (Ciorán, 1972: 36). De hecho, afirma tajantemente que "vivir con la idea del suicidio es estimulante" (Casado, 2010).

Para este:

La libertad, concebida en sus implicaciones últimas, plantea la cuestión de nuestra vida o de la de los otros; comporta la doble posibilidad de salvarnos o de perdernos. Pero no nos sentimos libres, no comprendemos nuestras oportunidades y nuestros peligros, más que en ciertos sobresaltos. Y es la intermitencia de esos sobresaltos, su rareza, lo que explica por qué este mundo no es más que un matadero mediocre y un paraíso ficticio. Disertar sobre la libertad no lleva a ninguna consecuencia, ni para bien ni para mal; pero sólo tenemos instantes para darnos cuenta de que todo depende de nosotros... La libertad es un principio ético de esencia demoníaca (Ciorán, 1972: 35-36).

En las palabras de la filósofo francesa Julia Kristeva, "el descubrimiento de que yo misma, en los planos más profundos de mis apetencias y deseos, soy incierta, carente de un centro fijo, dividida, no suprime mi capacidad de compromiso y de confianza, sino que la vuelve literalmente $-\mathrm{y}$ de ningún otro modo- lúdica" (Kristeva, 1987: 7-8).

Por su parte, para Foucault, no se puede dejar de considerar que la muerte, como el nacimiento, es para todos, y por tanto, cabría preguntarse: “¿por qué es necesario que nos hagan de esta certeza un azar, que toma por su carácter repentino o inevitable el aspecto de un castigo?" (Foucault, Un placer tan sencillo, 1999, pág. 200) La experiencia última de la muerte no tendría por qué quedar necesariamente circunscrita dentro de un "no se sabe cuándo ni cómo" o un "no hay más remedio", dando a entender que no hay más opción posible que la de someterse pasivamente a su "efectuación", sin dejar espacio para que se produzca, una "contra-efectuación". 1. La «contra-efectuación», afirma Deleuze, nos ofrece la posibilidad de «convertirnos en
la casi-causa de lo que se produce en nosotros.» La «efectuación» sería simplemente lo que nos ocurre, mientras que la «contra-efectuación» implicaría la posibilidad de crear un «sentido» desde el que poder experienciar lo que nos ocurre. (Quintanas, 2010, pág. 180) 
Precisamente, encuentra que:

Es inadmisible que no se nos permita a nosotros mismos preparar [la muerte] con todo el cuidado, la intensidad y el ardor que deseemos y con todas la complicidades que se nos antojen. (Foucault, Un placer tan sencillo, 1999: 200).

Al respecto se pregunta, ¿Por qué se nos obliga a dejar que sean el azar o los fríos protocolos de la técnica los que gobiernen el momento de la muerte? ¿Por qué nos resulta tan chocante que se pudiera llegar a deliberar sobre las diferentes posibilidades que existen de poner fin a la propia vida? ¿Por qué no dejar espacio para la expresión de las diversas opciones que más pudieran convenir a cada individuo concreto? De tal suerte, argumenta que las decisiones que se pudieran tomar sobre el momento de la muerte podrían ser el resultado de algo largamente meditado (Quintanas, 2010: 180). Es decir:

Hay que prepararla, componerla, fabricarla pieza a pieza, calcularla o, mejor, encontrar los ingredientes, imaginar, elegir, recibir consejo y trabajarla para hacer de ella una obra sin espectador que existe únicamente para mí, y sólo el tiempo que dure el más breve segundo de la vida. [...] Tenemos la oportunidad de disponer de ese momento absolutamente singular. Merece la pena ocuparse más de él que de cualquier otro: no para preocuparse o intranquilizarse sino para transformarlo en un placer desmesurado, cuya preparación paciente, sin descanso y también sin fatalidad, iluminará toda la vida (Foucault, Un placer tan sencillo, 1999: 200-201).

No obstante, cabe remarcar que Foucault desde el principio deja claro que cuando habla de la posibilidad de preparar el acontecimiento de nuestra muerte no se refiere al suicido por desesperación, al suicido como huida de la vida, como incapacidad para vivirla. El suicidio al que apela nada tiene que ver con la frustración que puede generar la vida o con el fracaso de la voluntad de vida (Quintanas, 2010: 181). Argumenta que:

Si quieren ustedes que disminuya realmente el número de suicidios, hagan que sólo se mate la gente por una voluntad reflexiva, tranquila y liberada de incertidumbre. No hay que dejar el suicidio en manos de personas desgraciadas e infelices que amenazan con arruinarlo, estropearlo y hacer de este una miseria. (Foucault, Un placer tan sencillo, 1999: 200)

\section{Conclusiones}

En definitiva, para Foucault, no se puede aceptar que se nos prive de decidir sobre el sentido y el valor de este acontecimiento que clausura nuestra vida. En consecuencia, habría que abogar por una ética estética de sí que asuma unas formas reflexivas que adopten la autonomía en el sentido de una voluntad reflexiva, tranquila, liberada de incertidumbre con la cual superar esa idea de la propia muerte estereotipada y banalizada que la ha convertido en algo realmente deprimente, "como si la muerte debiera apagar cualquier esfuerzo de la imaginación". (Foucault, Un placer tan sencillo, 1999: 201).

Así, cabe reiterar que la intención no ha sido otra que motivar la reflexión multidisciplinar sobre el tema del suicidio y no sentar cátedra, de allí, que no se ha pretendido alcanzar conclusiones, sino, dejar abiertos los interrogantes. En ese mismo sentido, queda la tarea pendiente y fundamental de contrastar múltiples posturas con las cuales enriquecer la reflexión.

\section{Bibliografía}

Birán, M. d. (1932). OEuvres Philosophiques. Paris: Publiées par P. Tisserand.

Camus, A. (1994). El mito de Sísifo. Barcelona: Altaya. 
Casado, J. (2010). Emil Cioran: vivir con la idea del suicidio es estimulante. Aparte Rei. Revista de filosofia, 1-10.

Ciorán, E. (1972). Brevario de podredumbre. Barcelona: Taurus.

Cioran, E. (1990). Silogismos de la amargura. Barcelona: Tusquets.

Foucault, M. (1991). Historia de la sexualidad Vol. 1. México: Siglo XXI.

Foucault, M. (1999). Un placer tan sencillo. En M. Foucault, Obras esenciales, vol. III (págs. 199-201). Barcelona: Paidós.

Frank, M. (1995). La piedra de toque de la individualidad. Barcelona: Herder.

Gergen, K. J. (1991). El yo saturado. Barcelona: Paidós.

Gevaert, J. (1995). El problema del hombre. Salamanca: Sígueme.

Heidegger, M. (1975). Ser verdad y fundamento. Caracas: Ávila editores.

Kristeva, J. (1987). In the Beginning was Love. New York: Columbia University Press.

Lyons, J. O. (1978). The Invention of the Self. Illinois: Southern Illinois University Press.

Quintanas, A. (2010). El tabú de la muerte y la biopolítica según M. Foucault. $\Delta \alpha l^{\prime} \mu \omega v$. Revista Internacional de Filosofia, 171-182.

Taylor, C. (1996). Las fuenstes del yo. Barcelona: Paidós. 